\title{
CONTINUIDAD Y CAMBIO EN LOS LEGISLATIVOS LOCALES MEXICANOS ${ }^{1}$
}

\author{
Ernesto Hernández Norzagaray*
}

Fecha de recepción: septiembre de 1999

Fecha de aceptación y versión final: diciembre de 1999

Resumen: El objetivo de este ensayo es el de exponer cuáles son los mecanismos de cambio dentro de la continuidad en los legislativos locales mexicanos. También, la identificación de las transformaciones que se han dado en las preferencias electorales y la conformación de nuevos tipos de integración en los 32 congresos locales. Este vértice insospechado hasta hace algunos años, ha planteado nuevos problemas y retos, que reclaman un nuevo tipo de arreglo entre los partidos políticos para superar el rezago institucional que se vive en el poder legislativo sobre todo cuando los realineamientos electorales, generalmente, no se han traducido en leyes orgánicas y reglamentos interiores de gobierno más eficaces que garanticen un mayor y mejor desempeño parlamentario. En suma, el trabajo obedece a la necesidad de explorar los territorios institucionales de la transición mexicana.

Palabras clave: Congreso, gobierno, liberalización, continuidad y cambio.

Abstract: The goal this of this essay is to demostrate wich are the mecanisms of change within continuity in the legislative local branches of Mexico. Also, I want to show how this changes have been held in electoral choices and how the new models of integration, of the 32 local representative houses are built up. This new and unsuspected situation has set up on the political table new challenges and problems that demand a kind of new deal among the political parties to overcome to leave behind institutional that is predominant in contemporary Mexico. In general terms the electoral realigments has not been translated in new laws and rules of government that could make more efficient and solid parlamentary work. Therefore, this paper has been written with the pourpose of exploring the new institutional territories the Mexican transition.

Key words: Congress, government, continuity and change.

Si en México los años ochenta se caracterizaron por el fin del sistema de partido "hegemónico-pragmático", del que nos hablaba entonces Giovanni Sartori ${ }^{2}$, los noventa han sido de experiencias de alternancia que han modificado sustancialmente la geografía electoral del país y los equilibrios de la representación en los congresos federal y locales. Sin embargo, esta tendencia, que cada día toma mayor carta de naturalización en los comicios y congresos locales, no se ha traducido en una rápida transformación en el sistema de relaciones institucionales que dominen el trabajo parlamentario; por el contrario, en los congresos se mantiene el sistema de reglas del viejo régimen político que ha provocado una atonía de la competencia electoral y el sistema de representación, lo que frecuentemente se traduce en un bajo rendimiento de los órganos legislativos.

Justamente, los objetivos de este ensayo son, en primer término, exponer los mecanismos de cambio dentro de la continuidad en los legislativos locales; en segundo, reconocer los cambios que se han dado en las preferencias electorales y la conformación de una nueva geografía política regional. Y al final, identificar los grandes vacíos de las leyes orgánicas y los reglamentos de los congresos locales, tratando de encontrar explicaciones plausibles sobre su rendimiento parlamentario.
Este trabajo, por lo demás, se inscribe en los nuevos estudios que se vienen realizando sobre la realidad política mexicana y, en este caso, la opción de análisis es la de comparar los trazos más gruesos del vasto sistema de competencia interpartidaria regional, como también los correspondientes a la vida institucional de los congresos locales. Se trata, en suma, de profundizar localmente en la tesis de Badie y Hermet, quienes con agudeza sostienen que "cada parlamento, cada partido, cada modo de movilización política está marcado por la huella de una historia, de una cultura que los distingue de los parlamentos, partidos y modos de movilización propios de otros” (Badie y Hermet, 1993:7) estados y países.

1. Artículo presentado en el IV Congreso de la Asociación Española de Ciencia Política y de la Administración.

* Profesor-Investigador del Centro de Investigaciones Sociales de la Escuela de Ciencias Sociales de la Universidad Autónoma de Sinaloa (México).凶norzagaray@csoliales.maz.vasnet.mx

2. En efecto, Giovanni Sartori al analizar las tipologías de partido único reconocía el carácter atípico del PRI por lo que lo clasifica como un partido "hegemónico-pragmático", es decir, un sistema "tan inclusivo y agresivo que se acerca a un partido tipo amalgama", es decir, como el único protagonista de una disposición centrada en torno a un solo partido rodeado por una periferia de partidos secundarios". Partidos y Sistemas de Partidos I. Madrid: Alianza Universidad (1976) P. 280 y ss. 
La importancia de este tema tiene que ver, en primera instancia, con el escaso desarrollo de las investigaciones sobre el Congreso federal y local ${ }^{3}$, especialmente de este último, del cual conocemos muy pocos esfuerzos académicos por comprender su dinámica y los mecanismos formales e informales de funcionamiento. Asimismo, por los retos institucionales que representan los cambios en las preferencias electorales en cuanto creadores de congresos con equilibrios diversos, lo que supone diferentes modalidades de inserción de las regiones en los procesos de transición a la democracia.

\section{PRESIDENCIALISMO Y CONGRESO EN MÉXICO}

La estabilidad del sistema político mexicano en este siglo tiene como fundamento el acuerdo de 1917, cuando, una vez terminada la lucha armada, los constitucionalistas se reunieron en Querétaro para establecer las bases económicas y de justicia social que habrían de gobernar al México posrevolucionario. En estos debates se puso de manifiesto el interés de las distintas facciones político-militares por establecer un sistema eficaz para evitar la perpetuación del poder, garantizando poderes amplios al presidente a fin de lograr la gobernabilidad política del país. El resultado (de estos debates) fue que las decisiones fundamentales de la sociedad mexicana no recaerían en un poder de excepción, sino en un presidente con amplios poderes constitucionales y metaconstitucionales, los cuales ejercería puntualmente sobre el gobierno y la administración pública. Del mismo modo, como parte de ese nuevo entramado institucional, el presidente dispondría de poderes discrecionales sobre los gobiernos de los estados y los poderes legislativos y judicial.

Este modelo de presidencialismo autoritario adopta una forma más acabada cuando en 1929 se constituye el Partido Nacional Revolucionario (PNR), que luego evolucionaría hacía el Partido de la Revolución Mexicana (PRM), para terminar en el Partido Revolucionario Institucional (PRI) que era una red que funcionaría como partido del Estado.

En esta lógica, el presidente cumpliría la primera regla del nuevo acuerdo, que era la no reelección, pero también estaba obligado a propiciar eficazmente la circulación de las élites políticas confederadas. El PRI, en cambio, en tanto maquinaria electoral tendría como principal responsabilidad garantizar la continuidad de la estructura del poder, la burocracia partidaria y la conservación del mito fundacional de la revolución mexicana (Paramio, 1991).

La continuidad del sistema no sería totalmente comprensible de no reconocer, desde su origen, el papel que habría de jugar la alternancia en el poder de las distintas redes políticas ${ }^{4}$. Las que en competencia soterrada y, en ocasiones, con las armas en la mano, cuando no de manera abierta, lucharían por el control de espacios del poder político del país.

El nacimiento del sistema político mexicano está íntimamente ligado a una estructura que es tejida por una red de poderes fácticos, los cuales defendían sus zonas de influencia regional pero que, con el paso del tiempo, fueron siendo sustituidas por la negociación y acuerdo entre los grupos de poder. En esa forma, la constitución del PNR y, más tarde, del PRM y PRI, está asociada a la articulación de esas redes que atravesaban el país mediante el establecimiento de clientelas políticas que garantizaban la unidad partidaria y la conservación del poder.

La fase culminante de este entramado de relaciones políticas y sociales está vinculado al gobierno de Lázaro Cárdenas, quién durante su mandato como presidente dio forma a un modelo de organización del poder caracterizado por los sectores del partido. Los sectores del PRI (obrero, campesino y popular) cumplían el papel de procesar la demanda social mediante un abigarrado y complejo sistema de relaciones políticas, como también de premios y castigos que se aplicaban puntualmente.

Más aun, durante su mandato queda perfectamente delineado el perfil de las instituciones presidencial y partidista. En lo sucesivo el papel del presidente deja de lado la incertidumbre que generaban las asonadas y la lucha soterrada por el poder para erigirse en el factotum del poder nacional en cuanto representante de la federación y eje en las relaciones entre el centro y los estados. El PRI, en tanto, conformado por los sectores tenía como tarea la de afianzar los vínculos entre el Estado y los distintos segmentos sociales pero sobre todo el control de los mecanismos de representación política.

La continuidad del sistema no sería comprensible de no reconocer que el espacio de negociación por excelencia entre el presidente y el partido es, al menos hasta 1988, el de la sucesión presidencial, ya que hasta entonces el relevo de las élites en el poder había sido ordenado sin violentar la estabilidad del sistema.

La clave de la continuidad a lo largo de más de 50 años tiene que ver fundamentalmente con una serie de acuerdos informales para mantenerse dentro del juego político: a saber:

1. El reconocimiento del presidente como “ jefe máximo de la revolución";

2. Brindar el apoyo incondicional al candidato que el presidente seleccionara como el sucesor;

3. Colaborar con la nueva red en el poder y;

4. Esperar pacientemente la nueva red del siguiente sexenio 5 .

Los congresos, federal y local, entonces, fueron desde su origen, además de un espacio de representación que permitía la gobernabilidad del país, la mejor garantía para la

3. Una evaluación sobre este particular la realiza Alonso LUTAMBIO (1996) en su texto Federalismo y Congreso en el cambio político de México. México: UNAM.

4. Para Larissa AdLer LOMNITZ y Frida GORBACH (1998:64) el concepto de red de poder "constituye un sistema de articulación política que comprende varios niveles de representación y participación y cuyos miembros se promueven recíprocamente alrededor del interés común de conservar el poder". Entre la continuidad y el cambio: el ritual de la sucesión presidencial".

5. Para una visión más amplia de ésta dinámica véase de Larissa ADLER y Frida GORBACH (1998): "Entre la continuidad y el cambio: el ritual de la sucesión presidencial”, en Revista Mexicana de Sociología, vol. 60, núm. 3, julio-septiembre. 
circulación de la élite gobernante así como el mecanismo más eficaz para el desempeño político.

\section{GOBIERNO Y CONGRESO LOCAL}

Los elementos más frecuentes de la continuidad política en los estados se encuentran en los usos y costumbres típicamente verticales que habían sido estructuradas. Grosso modo las que mencionaremos a continuación son las que más han permitido un determinado orden sistémico en una geografía múltiple y diversa:

1. El gobernador, quién fue habilitado desde los treinta mediante elecciones sin oposición, pero conforme a elecciones periódicas, era un producto de la negociación entre las redes de poder nacional quienes designaban, con la anuencia de las élites locales, al que tendría la responsabilidad de dirigir los destinos de esa región. El presidente funcionaba como el articulador de los intereses en pugna hasta hacerlos compatibles con los del sistema autoritario. En consecuencia, el gobernador debía más lealtad al presidente en turno que a sus electores. Incluso, en ciertas circunstancias, el poder del presidente era suficiente para removerlo del puesto y promover uno nuevo que reeditaba el ciclo.

2. Ya en funciones, una vez que cuenta con el apoyo político del presidente, era el responsable de administrar los equilibrios del poder regional. Su función tenía que ver con la garantía de la unidad de las redes políticas bajo su liderazgo e interpretar localmente las políticas federales.

3. El titular del ejecutivo estatal, por esa operación en cierta forma delegativa, se transforma en el jefe del partido en su estado y, por ende, en el depositario temporal del poder para promover sus distintas redes. Incluyendo casi siempre la propia. Sólo que, respetando los consensos regionales.

4. Las oposiciones que marginalmente se expresaban, cumplían con el ritual de la elección y su representación en el poder legislativo constituía una contribución a la legitimidad del régimen político.

5. El congreso local cumplía un papel mediático entre la demanda social y los designios del gobernante en turno, cuando no de las propias redes de poder.

\section{LA LIBERALIZACIÓN DEL SISTEMA POLÍTICO}

Sin embargo, esto que fue una constante durante el largo período de elecciones sin oposición vino cambiando paulatinamente como resultado del proceso de liberalización " que ha vivido el país desde finales de los setenta, cuando, producto del desgaste del sistema político, la crisis de legitimidad y la sobrecarga de la demanda se lleva a cabo la primera reforma política. Entre sus aportes se encuentra el hecho de que el sistema de partidos se eleva a rango constitucional y, con ello, se abre y flexibiliza la competencia electoral.

Más aun, los elementos de cambio en la continuidad del sistema los encontramos en las nuevas tendencias de preferencias electorales que modificaron el mapa político nacional, transformaron el sistema electoral, provocaron la ciudadanización de los órganos electorales y la normalización de la alternancia en varios niveles de gobierno.

En 1996, como parte de este proceso de maduración institucional, se logra la mayor reforma constitucional de que se tenga memoria en la historia del sistema político: la autonomía total de los órganos electorales; la protección de los derechos políticos de los ciudadanos; el control de la legalidad y la constitucionalidad de los actos en materia electoral; la separación de los temas y la sustancial mejora de los medios de lo contencioso electoral; la incorporación del Tribunal Federal Electoral al Poder Judicial; mejores condiciones de competencia mediante unos instrumentos más adecuados para fiscalizar, revisar y modular los gastos en las campañas de los partidos; mayor confiabilidad en el proceso electoral; el ajuste de las fórmulas de representación en el congreso restando los márgenes de sobre y subrepresentación de los partidos y la apertura a competencia electoral del gobierno de la ciudad de México?.

Estas reformas consolidaron el sistema de competencia, lo que permitió que el país entrara a la normalidad democrática, que venía siendo un viejo reclamo de la sociedad civil y política. En lo sucesivo, la experiencia de las elecciones frecuentemente se procesó institucionalmente y no, como había venido sucediendo, mediante la negociación entre las élites partidarias y regionales.

Asimismo, la constitucionalidad de los actos en materia electoral favoreció la modificación de los ordenamientos electorales en los estados de la federación, lo que significó la transformación de sistemas electorales con distintos niveles de apertura y flexibilidad para la competencia electoral ${ }^{8}$, como también una mayor certeza en los resultados electorales. Así, la representación ${ }^{y}$ adquiere una mayor credibilidad y, consecuentemente, el sistema político obtiene mayores cuotas de legitimidad.

El congreso local, entonces, manifiesta cambios en su composición producto de una mayor competencia partidaria y leyes más flexibles para la integración de las minorías.

6. La literatura politológica en torno al proceso de liberalización política es vasta como lo muestra una serie de trabajos académicos. Está el de Kevin J. MiddLeBRoOK (1998): “La liberalización política de un régimen autoritario: el caso de México”, en G. O'DONNELL, P.C. SCHMITTER y L. WHITEHEAD (comps), Transiciones desde un régimen autoritario: América Latina. Buenos Aires: Paidós. El de Soledad LoAEzA (1996): "Liberalización política mexicana", en COOK, María Lorena et al "Las dimensiones politicas de la reestructuración económica”. México: Cal y Arena y el de ROETT, Riordan (comp.) (1999): La Liberalización económica y Política de México. México, Siglo XXI Editores. En el nivel de los estados se encuentra el de autor de ésta ponencia (1997): La liberalización política mexicana: legislación y procesos electorales en los estados de Baja California, Michoacán y Sinaloa. México: EdiUAS

7. Véase de José Woldenberg (1997): “Alcances de la reforma electoral de 1996", Revista Sinaloense de Ciencias Sociales, Arenas, No. 1. México Universidad Autónoma de Sinaloa.

8. Véase del autor de este texto "La liberalización politica mexicana: legislación y procesos electorales en Baja California, Michoacán y Sinaloa (1978-1992)".

9. Asumimos la definición que nos ofrece Hannah PITKIN (1967) en su ya clásico trabajo The concept of Representation, University of California, Berkeley. Para PITKIN el concepto de representación tiene un carácter polisémico ya que puede ser considerado como: 1) cesión de autoridad; 2 ) responsabilidad; 3 ) representación, espejo o reproducción de una determinada realidad; 4) evocación simbólica y 5) acción en interés de alguien que no puede o no desea actuar personalmente. 
Sin embargo, este cambio vertiginoso en la composición de los congresos no vino a la par de una transformación de las estructuras institucionales, que siguieron siendo las mismas del viejo régimen político.

El cambio "vía elecciones", estaba visto. Garantizaba un congreso más plural, pero no la transformación de fondo de la propia institución que había sido construida con los rudimentos de una ingeniería institucional de sistema de partido casi único. Y por esa misma razón eran insuficientes para procesar los cambios que se venían dando en el tipo de relación que históricamente había tenido el poder Legislativo frente al Ejecutivo.

\section{LAS PREFERENCIAS ELECTORALES: ORIEN- TACIÓN DEL VOTO Y COMPETITIVIDAD ELEC- TORAL}

Los dos últimos procesos electorales celebrados en los estados federados tienen como algunas de sus características principales la de una baja fragmentación y una alta volatilidad del voto, lo que ha impreso al sistema de representación política un gran dinamismo que ha puesto a prueba sus viejos limites de funcionamiento y abierto una verdadera caja de Pandora de donde han salido todo tipo fórmulas de equilibrios que determinan las modalidades de la transición a la democracia en la provincia mexicana.

Justamente, producto del dinamismo que han tenido las elecciones en este país, caracterizado hasta principios de los años ochenta por ser un sistema hegemónico sin oposición, tiene un nuevo mosaico de equilibrios políticos que ha puesto en entredicho la lógica que funcionaba eficazmente como ordenador de las piezas del sistema.

Los elementos de cambio en la continuidad del sistema político regional podríamos identificarlos en dos niveles: uno, el correspondiente a la normativa electoral, que si bien ha manifestado cambios significativos y, en algunos casos, de una mayor profundidad en un estado frente a otro, lo cierto es que tiene frecuentemente omisiones y sesgos que le garantizan al PRI una sobrerrepresentación en los congresos locales y, dos, que los realineamientos electorales de ésta década favorecieron nuevas mayorías en los estados, lo que se ha traducido en una representación que contrasta con la uniformidad del pasado.

Hoy, como veremos más adelante, en el congreso local hay casos de mayoría relativa de los tres principales partidos, mayoría absoluta de un solo partido, bipartidistas, tri y cuatripartidistas.

En suma, la experiencia de gobiernos divididos representa el mejor ejemplo de transición a la democracia pero también el principal reto que entraña el proceso de cambio, en cuanto significa un conjunto de problemas institucionales para garantizar la gobernabilidad de las entidades federativas mexicanas.

\section{ORIENTACIÓN DEL VOTO}

Las sucesivas reformas que se llevaron a cabo en los estados de la federación, ampliaron el espectro de los partidos políticos. Sin embargo, los resultados electorales muestran una fuerte tendencia hacia la concentración del voto en dos de ellos, sea en un caso la mancuerna PRI-PAN y en el otro la del PRI-PRD.

El cambio en la continuidad obedece a todo menos al bipartidismo que caracterizó todavía la década de los ochenta donde el PRI y el PAN se veían muy superiores a las otras opciones de izquierda y derecha sino a que en algunas regiones del país se puso de manifiesto el peso del PRD, lo que significó que el bipartidismo de antaño se rompió y dio paso a una nueva correlación de fuerzas.

Ningún caso de bipartidismo fue favorable para que el PAN y el PRD dejaran al PRI en una tercera posición. A lo sumo, la incapacidad de derrotar por si sólo al PRI ha estimulado en los estados coaliciones entre el PAN y PRD, como también entre el PRD y el PT, el PAN y el PVEM, donde los resultados han demostrado que es posible derrotar al PRI como sucedió en 1998 en Aguascalientes y Zacatecas y Baja California y, en 1999 en Tlaxcala y Nayarit.

Sin embargo, la excepción a las reglas muestra el lugar privilegiado que sigue ocupando el PRI en la competencia electoral. Aunque es de destacar el peso mayoritario que el PAN y el PRD tienen en algunos estados de la República donde son gobierno y el PRI es siempre la primera minoría (véase el cuadro 1); asimismo, su papel secundario en muchos de los congresos locales.

La concentración del voto del PRI y el PAN (que es la mayoría) corresponde a un tipo de estado muy diverso donde predominan aquellos estados en los que existen las mayores concentraciones urbanas -con excepción de la capital de la república- y las más grandes bolsas de población rural. En sentido estricto mientras el PRI tiene sus apoyos más estables en las zonas rurales y sufre de las mayores resistencias en la medida en que éstas son más urbanas, el PAN funciona en sentido inverso, ya que, salvo en algunos estados, su fuerza la tiene en los centros urbanos y, especialmente, en las capitales de los estados del centro-norte y norte del país. Por su parte, la relación PRI-PRD se da en aquellos estados donde además del peso que tiene la población rural es manifiesta la baja participación que tienen respecto al PIB, con excepción, claro, del Distrito Federal. Una situación, más o menos similar, es aquella donde domina el PRD sobre el PRI.

La quiebra de la hegemonía del PRI generó realidades nuevas en los congresos locales, producto del fin del llamado "gobierno unificado" que garantizaba en todos los estados la mayoría calificada y, consecuentemente, el predominio absoluto de este partido sobre el resto del sistema de partidos. Hoy, sólo en los estados de Chiapas, Puebla y Veracruz, el PRI mantiene la mayoría calificada, en otros diecinueve la mayoría relativa y en diez se encuentra como primera minoría (cuadro 2).

Este escenario, además de romper con la uniformidad que había caracterizado a los congresos locales, plantea los problemas inherentes a los llamados gobiernos divididos ${ }^{10}$

10. Entendemos por gobiernos divididos como lo utilizan Ulises CARRILlo y Alonso LUJAMBIO (1998). Para ellos se entiende por "gobierno dividido" aquel en el que, en el marco de un régimen de división de 


\begin{tabular}{|c|c|c|}
\hline \multicolumn{3}{|c|}{ 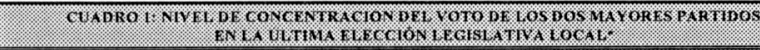 } \\
\hline $15 \% 1000$ & NIVELL DE CONCENTRACION & 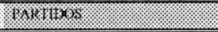 \\
\hline 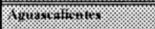 & 88.11 & 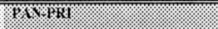 \\
\hline 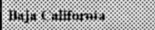 & 82.3 & $=+x+1+24$ \\
\hline 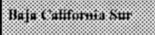 & 83.65 & 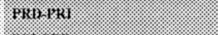 \\
\hline 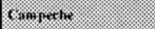 & 87.21 & 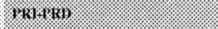 \\
\hline restiritr. & 80.55 & 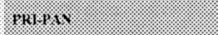 \\
\hline ritin: & 82.70 & mentriti: \\
\hline (Minpus: & 78.98 & thetrito \\
\hline crituanial & 80.23 & $\operatorname{rix} \pi+x$ \\
\hline 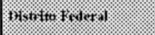 & 62.00 & $\ln 2 \pi+1$ \\
\hline 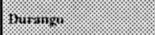 & 70.20 & 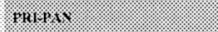 \\
\hline traminame & 78.17 & $1+1+1+21$ \\
\hline 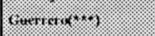 & $8+24$ & 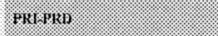 \\
\hline 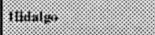 & 80.90 & 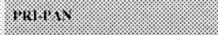 \\
\hline hairion: & 78.34 & $\pi x+1 \times \pi$ \\
\hline 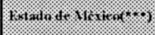 & 67.43 & mant: \\
\hline 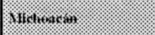 & 68.77 & 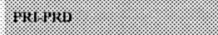 \\
\hline Hinrtios: & 73.05 & Fritritin \\
\hline manti & 20.50 & $\cot (x \cdot \ln 1$ \\
\hline limintin & 80.50 & $10.17: 1213$ \\
\hline 1\%..... & 84.86 & 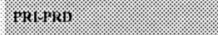 \\
\hline Fintwi, & 78.18 & mertitis \\
\hline 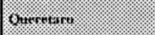 & 85.63 & Haxtix \\
\hline (onarara kai. & 75.85 & 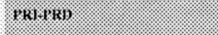 \\
\hline 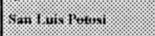 & 81.86 & ratrits \\
\hline sinatus & 78.57 & mrintis \\
\hline $2 m$ & 6.2.15 & rarri: \\
\hline trinment & ж.62 & ratratin \\
\hline T.minim & 77.98 & 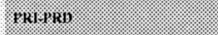 \\
\hline rinat: & 70.37 & (mon \\
\hline 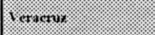 & 73.06 & mertron \\
\hline Yunanim & 86.58 & mantid \\
\hline 2ranka & $79 .+7$ & kкі2 rki \\
\hline
\end{tabular}

de estados de la federación mexicana ${ }^{\prime \prime}$, que vienen siendo los que se derivan de la crisis del sistema presidencialista unitario. Esto es, es la crisis de un modelo donde el Ejecutivo cumple las funciones de Jefe de Estado y Jefe de Gobierno, por lo que se transforma en el vértice del poder político.

En ésta lógica -que es más acusada en sistemas presidencialistas autoritarios, como el mexicano- el papel del Congreso es limitado porque no puede dar voto de censura, como sucede frecuentemente en sistema políticos parlamentarios donde existe un Jefe de estado y un Jefe de Gobierno y donde los miembros del gabinete lo son también del parlamento. Asimismo, cuando el gabinete está integrado por los directivos de los partidos mayoritarios o, en su defecto, por las coaliciones parlamentarias que hacen gobierno.

Es la crisis del tipo de relación que cuando menos hasta hace pocos años era patética por el gran número de gobiernos interinos -sólo durante el salinismo hubo trece gobiernos interinos y algunos de ellos reiterados, como sucedió en Chiapas- que poblaban el paisaje nacional y, contrariamente a un principio constitucional que justificaría esos interinatos, eran producto de decisiones políticas del presidente de la República, contraviniendo el principio de soberanía de los estados y la separación de poderes de todo sistema presidencialista democrático ${ }^{12}$.

Grosso modo esta crisis es de dos tipos:

1) El propiamente político que tiene que ver con los incentivos de los partidos políticos para apoyar en el gobierno a su adversario;

2) El tipo de coaliciones posibles que pudieran crease en cada uno de los congresos locales.

El sistema presidencialista mexicano, como lo señalamos, otorga al presidente poderes constitucionales y metaconstitucionales, lo que era bastante visible en el ejercicio de los llamados "gobierno unificados"; sin embargo, los cambios electorales que se han venido presentando en los estados de la federación, pero también en la legislatura federal, han puesto en entredicho la uniformidad en el sistema político y, consecuentemente, la ineficacia del verticalismo que dominaba las relaciones políticas tradicionales.

En efecto, este sistema presidencialista funcionó con eficacia -y, con pequeños márgenes de represión selectivadurante varías décadas, lo que dotó a los sucesivos gobernantes de legitimidad para la acción de gobierno. La explicación más socorrida la encontramos en los incentivos que ofrecía el sistema y la extraordinaria capacidad del PRI, a través de los sectores, de procesar la demanda social y polí tica. Sin embargo, esto cambia cuando surgen actores políticos con su propia organización y demandas que no se procesan en los sectores del partido oficial pero, además cuando lo hicieron en competencia por espacios de representación política.

Justamente, fue en el congreso federal y local, antes que en los municipios y los estados, donde se hizo efectivo un cambio en la continuidad del sistema de representación política.

La evolución de la representación testimonial de los ochenta abrió paso a fracciones parlamentarias con identidad y peso propio, lo que supuso un sistema de incentivos diferente o, en su caso, reserva para la colaboración con el partido en el gobierno.

Los argumentos esgrimidos por Linz ${ }^{13}$ para criticar el sistema presidencialista, al mismo tiempo que mostrar las virtudes del sistema parlamentario, tienen un valor cuanto que el incentivo que pudiera tener un partido opositor con un peso en el congreso pueden ser muy bajos simple y sencillamente porque corre el riesgo de que si coopera y el resultado de dicha cooperación resulta exitoso los beneficios políticos-electorales son capitalizados por el ejecutivo y su partido. En sentido contrario, si la cooperación fracasa, todos los miembros de la coalición pagan los costos políticos. Linz, como se sabe, plantea como alternativa al modelo

poderes, el partido que llevó al presidente a ocupar la titularidad del poder ejecutivo no cuenta con el control mayoritario, esto es, con por lo menos $50 \%+1$ de los escaños de la Asamblea Legislativa en sistemas unicamerales y en por lo menos una de dos cámaras en sistemas bicamerales -en nuestro caso que estudiamos el congreso local, por lo tanto, tiene que ver con un sistema unicameral-. Aquí entendemos, -agregan los autores- por "gobierno dividido" todo aquel en el que el partido del presidente no cuenta con el control mayoritario en por lo menos una de las dos cámaras de congreso. Para el caso de nuestro estudio sería que el gobernador no cuenta con el apoyo de su partido en la cámara local. "La incertidumbre cons titucional. Gobierno dividido y aprobación presupuestal en LVII legislatura del Congreso Mexicano, 1997-2000", en Revista Mexicana de Sociologia, vol. 60, num. 2, abril-junio, p.239.

11. Véase el trabajo de Alonso LuJAMBIO (comp.) (1996): Gobierno divididos en la federación mexicana. México: UAM-IFE-Colegio Nacional de Ciencias Políticas y Administración Pública. En México desde 1989 han existido gobiernos divididos en Baja California (1989,1992, 1995 y 1998), Baja California Sur (1993-1996), Aguascalientes (1995-1998), Estado de México (1996-1999), Morelos (1997-2000), Sonora (1997-2000) Coahuila (1997-2000), Colima (1997-2000), Guanajuato 1991-1994, 1994 1997 y 1997-2000), Jalisco (1997-2000), Zacatecas (1998-2001), Tlaxcala (1998-2001).

12. Véase de Ernesto Hernández NorZAGARAY, ob cit, pp. 33-93.

13. Véase Juan J.Linz y Arturo VALENZUELA (comps) (1994): The failure of presidential democracy. Comparative Perspectives. Baltimore: John Hopkins University Press. 
presidencialista el parlamentario como un mecanismo que garantiza costos pero también beneficios para la coalición de gobierno ${ }^{14}$.

Esto llevado a la práctica puede terminar con una parálisis legislativa donde las estrategias no cooperativas de los partidos se impongan provocando un bajo rendimiento legislativo. A la LVII legislatura del Congreso de la Unión ${ }^{15}$, por ejemplo, se le ha acusado frecuentemente de una baja producción de leyes producto de la falta de cooperación de las fracciones parlamentarias para aprobar las iniciativas del ejecutivo, como también la de ellos mismos. Y esto seguramente es una constante en los gobiernos divididos de los estados, sobre todo cuando la instalación del nuevo gobierno se encuentra sometido a la lógica del desgaste poselectoral.

Aun así, la experiencia reciente en los estados favoreció dos tipos de dinámicas: una, donde se dieron manifestaciones de una nueva cultura de negociación entre los partidos y, otra, que generó virtualmente una parálisis legislativa en algunos congresos locales.

\section{CONGRESOS LOCALES CON MAYORÍA PRIISTA}

En los estados con congreso de mayoría priista (como podemos apreciar en el cuadro 2), existen cuatro tipos de entidades que es conveniente identificarlas para los fines de este trabajo: están los estados donde el PRI cuenta con mayoría calificada, donde se mantienen incólumes los incentivos hacia dentro de la élite partidaria; están los de mayoría absoluta donde mantiene control pero requiere de establecer puentes con otros partidos con el fin de sacar iniciativas que exigen la reforma constitucional; están aquellos donde es el partido con el mayor número de legisladores, pero se encuentra en desventaja numérica comparativamente al total de la oposición y; por último, está el caso de Zacatecas donde el gobernador es perredista pero el congreso de mayoría priista

La experiencia grosso modo en cada una de estas categorías es la siguiente. En el primer caso, aun cuando hay un cambio en las formas políticas se mantienen las tradiciones autoritarias de un sistema de partido casi único, lo que ha ocasionado no pocos diferendos entre el PRI y los partidos de oposición, quienes frecuentemente alegan la parcialidad de los organismos electorales y la sobrerrepresentación del partido, manteniendo viva la llama del conflicto y las estrategias congresionales no cooperativas; el caso más emblemático fue el de Huejotzingo en Puebla donde se tensó la cuerda de las relaciones políticas nacionales cuando el PAN se negó a aceptar los resultados electorales de ese municipio creándose una de las más curiosas crisis políticas de principios del sexenio.

En el segundo, que ya no sólo involucra al PRI, sino al PAN y el PRD, en tanto partidos en el gobierno de varios estados y el Distrito Federal, la experiencia indica que en ellos se han favorecido los acuerdos entre las fracciones parlamentarias, pero escasamente se ha llevado a cabo un proceso de reingeniería institucional que favorezca el trabajo legislativo más allá de una legislatura.
La tercera categoría es donde se han suscitado los mayores problemas, sobre todo cuando las mayorías parlamentarias tomaron en sus manos decisiones que contravenían los intereses del PRI, como son los casos de Morelos, donde la mayoría parlamentaria prácticamente echó del poder al gobernador priista y en Sonora, donde el inicio de la legislatura estuvo plagada de conflictos, producto de la conformación de un bloque opositor en la cámara local que detentaba la mayoría del congreso.

\begin{tabular}{|c|c|c|c|c|c|c|}
\hline \multirow{3}{*}{$\begin{array}{c}\text { Estatos } \\
\text { Campectie }\end{array}$} & \multicolumn{4}{|c|}{ 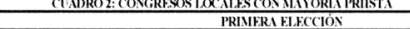 } & \multicolumn{2}{|c|}{ SEGGINDAFLECCOÓN } \\
\hline & Elecciones & Partidos & Totess & Escaños & Totos & Fiscatio \\
\hline & 1994 y 1997 & $\begin{array}{l}\text { PRI } \\
\text { PAN } \\
\text { PRI } \\
\text { Otros }\end{array}$ & & & $\begin{array}{l}48.01 \\
3.12 \\
31.22\end{array}$ & $\begin{array}{c}19 \\
3 \\
12\end{array}$ \\
\hline Cosaluilu & $1994(\cdot \cdots)$ y 1997 & $\begin{array}{l}\text { PRI } \\
\text { PAN } \\
\text { PRI } \\
\text { Orros }\end{array}$ & $\begin{array}{l}50.72 \\
29.83 \\
11.29\end{array}$ & $\begin{array}{c}19 \\
1\end{array}$ & & $\begin{array}{c}16 \\
10 \\
2 \\
2\end{array}$ \\
\hline Colima & 1994 y 1997 & $\begin{array}{l}\text { PRI } \\
\text { PAN } \\
\text { PRD }\end{array}$ & $\begin{array}{l}55.32 \\
25.36 \\
13.099\end{array}$ & $\begin{array}{c}12 \\
5 \\
2\end{array}$ & $\begin{array}{l}13.6 \\
39.1 \\
17.1\end{array}$ & $\begin{array}{c}10 \\
7 \\
3\end{array}$ \\
\hline Chiapsas & 1994 y 1997 & $\begin{array}{l}\text { PRI } \\
\text { PRIN } \\
\text { PRID } \\
\text { Orros }\end{array}$ & $\begin{array}{l}77.13 \\
8.60 \\
32.64\end{array}$ & $\begin{array}{l}26 \\
5 \\
6 \\
3\end{array}$ & $\begin{array}{l}51.29 \\
14.39 \\
27.69\end{array}$ & $\begin{array}{l}26 \\
5 \\
6 \\
3\end{array}$ \\
\hline Chiluahua & 1995 y 1998 & $\begin{array}{l}\text { PRI } \\
\text { PAN } \\
\text { PRD } \\
\text { Orros }\end{array}$ & 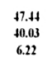 & $\begin{array}{l}15 \\
7 \\
1\end{array}$ & $\begin{array}{l}7.38 \\
71.85 \\
7.27\end{array}$ & $\begin{array}{l}19 \\
9 \\
5\end{array}$ \\
\hline Duraugo & 1995 y 1998 & $\begin{array}{l}\text { PRI } \\
\text { PAN } \\
\text { PRID } \\
\text { PT }\end{array}$ & $\begin{array}{l}35.99 \\
31.64 \\
9.82 \\
20.86\end{array}$ & $\begin{array}{c}13 \\
6 \\
1 \\
5\end{array}$ & $\begin{array}{l}3.9 .9 \\
30.3 \\
8.4 \\
21.3\end{array}$ & $\begin{array}{c}14 \\
5 \\
2 \\
1\end{array}$ \\
\hline Giucrerero & $1996\left({ }^{\circ}\right)$ y $1999(\cdot *)$ & $\begin{array}{l}\text { PRI } \\
\text { PAN } \\
\text { PRD } \\
\text { Otros }\end{array}$ & $\begin{array}{l}99.53 \\
82.8 \\
34.71\end{array}$ & $\begin{array}{l}24 \\
1 \\
2\end{array}$ & & 11 \\
\hline Ilidalago & $1996(\cdot \cdots)$ y 1999 & $\begin{array}{c}\text { PRI } \\
\text { PRN } \\
\text { PRIMT }\end{array}$ & $\begin{array}{l}54.15 \\
15.88 \\
15.015\end{array}$ & 18 & $\begin{array}{l}53.31 \\
27.59 \\
17.02\end{array}$ & $\begin{array}{c}18 \\
8 \\
4\end{array}$ \\
\hline Fistado de Mesikn & 1996 y 1999 & $\begin{array}{l}\text { PRI } \\
\text { PAS } \\
\text { PRID } \\
\text { Orrow }\end{array}$ & 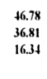 & $\begin{array}{l}20 \\
11 \\
10 \\
4\end{array}$ & $\begin{array}{l}37.26 \\
30.17 \\
21.59\end{array}$ & $\begin{array}{l}20 \\
11 \\
10 \\
4\end{array}$ \\
\hline Mikwaracin & 1995 y 1998 & $\begin{array}{l}\text { PRI } \\
\text { PAN } \\
\text { PRID } \\
\text { Otrow }\end{array}$ & $\begin{array}{l}37.79 \\
25.88 \\
32.50\end{array}$ & $\begin{array}{l}16 \\
? \\
?\end{array}$ & $\begin{array}{l}36.92 \\
25.28 \\
31.75\end{array}$ & $\begin{array}{c}18 \\
4 \\
7 \\
1\end{array}$ \\
\hline Oaxica & 1995 y 1998 & $\begin{array}{l}\text { PRI } \\
\text { PAN } \\
\text { PRID } \\
\text { Orrow }\end{array}$ & $\begin{array}{l}51.55 \\
12.01 \\
21.62\end{array}$ & $\begin{array}{l}25 \\
5 \\
9 \\
3\end{array}$ & $\begin{array}{l}\begin{array}{l}18.91 \\
11.13 \\
35.95\end{array} \\
\end{array}$ & $\begin{array}{c}25 \\
4 \\
13 \\
0 \\
0\end{array}$ \\
\hline Puchat & 1995 y 1998 & $\begin{array}{l}\text { PRI } \\
\text { PRIN } \\
\text { PRD } \\
\text { Otrow }\end{array}$ & $\begin{array}{l}48.88 \\
36.54 \\
9.75\end{array}$ & $\begin{array}{c}22 \\
14 \\
2 \\
1\end{array}$ & $\begin{array}{l}52.57 \\
27.61 \\
11.84\end{array}$ & $\begin{array}{l}26 \\
8 \\
3 \\
2\end{array}$ \\
\hline Quintana Roo & 1996 y 1999 & $\begin{array}{l}\text { PRI } \\
\text { PAN } \\
\text { PRID }\end{array}$ & $\begin{array}{l}55.51 \\
31.23 \\
9.28\end{array}$ & $\begin{array}{c}11 \\
6 \\
3\end{array}$ & $\begin{array}{l}15.18 \\
17.31 \\
29.67\end{array}$ & $\begin{array}{l}15 \\
2 \\
?\end{array}$ \\
\hline Sun I.ais Potosi. & $1994(\cdot \cdots)$ y 1997 & $\begin{array}{l}\text { PRI } \\
\text { PAN } \\
\text { PRDD }\end{array}$ & $\begin{array}{l}65.66 \\
21.10 \\
2.56\end{array}$ & 11 & 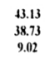 & $\begin{array}{l}14 \\
10 \\
2\end{array}$ \\
\hline Nimalau & 1995 y 1998 & $\begin{array}{l}\text { P'RI } \\
\text { PAN } \\
\text { PRDD }\end{array}$ & $\begin{array}{l}43.69 \\
40.05 \\
13.36\end{array}$ & $\begin{array}{c}21 \\
13 \\
4\end{array}$ & $\begin{array}{l}16.77 \\
31.10 \\
18.66\end{array}$ & $\begin{array}{c}24 \\
11 \\
5\end{array}$ \\
\hline Somora & $1994($ ()ㅗ : 1997 & $\begin{array}{l}\text { PRI } \\
\text { PRA } \\
\text { PRII }\end{array}$ & $\begin{array}{l}46.15 \\
31.85 \\
16.12\end{array}$ & $\begin{array}{l}77 \\
4\end{array}$ & $\begin{array}{l}31.77 \\
31.68 \\
26.55\end{array}$ & $\begin{array}{l}\text { it } \\
10 \\
9\end{array}$ \\
\hline Talasasca & $1994(\cdot 0)$ ) 1997 & $\begin{array}{l}\text { P'RI } \\
\text { PAII } \\
\text { I'RII }\end{array}$ & $\begin{array}{l}55.26 \\
3.60 \\
39.07\end{array}$ & $\begin{array}{l}16 \\
2\end{array}$ & $\begin{array}{r}55.26 \\
1.04 \\
41.36\end{array}$ & $\begin{array}{l}19 \\
1 \\
11\end{array}$ \\
\hline Tamaulipas & $1995 \mathrm{y} 1998$ & $\begin{array}{l}\text { PRI } \\
\text { PAI } \\
\text { PRD } \\
\text { Orow }\end{array}$ & $\begin{array}{l}49.10 \\
35.09 \\
7.29\end{array}$ & $\begin{array}{l}20 \\
? \\
3 \\
2\end{array}$ & $\begin{array}{l}50.29 \\
1+39 \\
27.69\end{array}$ & $\begin{array}{l}20 \\
6 \\
6 \\
0\end{array}$ \\
\hline Thaxcala & 1995,1998 & $\begin{array}{l}\text { PRI } \\
\text { PAI } \\
\text { PRII } \\
\text { Otrow }\end{array}$ & $\begin{array}{l}50.91 \\
18.01 \\
7.29\end{array}$ & $\begin{array}{l}19 \\
4 \\
4 \\
5\end{array}$ & $\begin{array}{l}13.46 \\
13.26 \\
26.91\end{array}$ & $\begin{array}{c}17 \\
1 \\
7 \\
4\end{array}$ \\
\hline Veracruz & 1995 y 1998 & $\begin{array}{l}\text { PRI } \\
\text { PAS } \\
\text { PRID }\end{array}$ & $\begin{array}{l}53.18 \\
15.29 \\
1.29\end{array}$ & $\begin{array}{l}28 \\
7 \\
4\end{array}$ & $\begin{array}{l}+6.19 \\
26.87 \\
20.27\end{array}$ & $\begin{array}{l}27 \\
9\end{array}$ \\
\hline lucettin & $1995(\cdot \cdots)$ y 1998 & $\begin{array}{l}\text { PRI } \\
\text { PAN } \\
\text { PRDD }\end{array}$ & $\begin{array}{c}50.02 \\
\begin{array}{c}5.55 \\
3.35\end{array}\end{array}$ & $\begin{array}{l}8 \\
7\end{array}$ & $\begin{array}{r}53.99 \\
36.99 \\
7.91\end{array}$ & $\begin{array}{l}15 \\
8 \\
2\end{array}$ \\
\hline Zacattcas & $1999-1998$ & $\begin{array}{l}\text { PRI } \\
\text { PRA } \\
\text { PRI } \\
\text { Otrow }\end{array}$ & $\begin{array}{l}28.69 \\
18.17 \\
6.79\end{array}$ & $\begin{array}{l}201 \\
6 \\
2 \\
2\end{array}$ & $\begin{array}{r}36.51 \\
12.33 \\
42.96 \\
1.20\end{array}$ & $\begin{array}{l}12 \\
6 \\
10 \\
2\end{array}$ \\
\hline 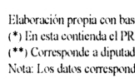 & 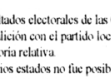 & $\begin{array}{l}\text { elinstituses } \\
\text { erD ai PT } \\
\text { s. }\end{array}$ & & & & \\
\hline
\end{tabular}

14. Véase el trabajo de Simón PACHANO (1998): "Presidencialismo y parlamentarismo". En Revista Mexicana de Sociología. Vol. 60, núm. 3 (julio-septiembre). México: IIS-UNAM.

15. El Financiero, 10 de Mayo y 17 de Agosto 1998. 


\section{CONGRESOS LOCALES CON MAYORÍA PANISTA}

Los resultados electorales de los comicios de Baja California en 1989 no sólo dieron como ganador a Ernesto Ruffo, el primer gobernador de un partido opositor, en este caso el PAN, sino al primer congreso donde la mayoría absoluta no correspondía al PRI, la misma que luego sería ratificada en tres ocasiones consecutivas.

Este triunfo emblemático de la oposición histórica estimuló la idea en el panismo de que los triunfos vendrían en cascada, sin embargo, esto no sucedió en la magnitud que se esperaba en los noventa. Sólo aconteció en Chihuahua y Guanajuato en 1995 y 1994 respectivamente, donde gobernaron con mayoría priista en el congreso local.

Fue hasta la segunda mitad de los noventa cuando los triunfos locales se hilvanaron en distintas regiones del país - contraviniendo la idea de que su influencia se encontraba principalmente en el norte del país- y eso propició, mayorías parlamentarias panistas de dos tipos: aquellas donde se obtuvieron mayorías absolutas y, las otras, que eran técnicamente gobiernos divididos.

La experiencia legislativa panista, en los casos de mayorías absolutas, se caracteriza por los esfuerzos, como es el caso de Baja California, por sacar adelante iniciativas que no implican reformas constitucionales y, en los otros, llevar a cabo negociaciones que permitan acuerdos que garantizaran la gobernabilidad del estado.

\begin{tabular}{|c|c|c|c|c|c|c|}
\hline \multirow[b]{2}{*}{ Estados } & & \multicolumn{3}{|c|}{ PRIMERA ELECCIÓN } & \multicolumn{2}{|c|}{ SEGUNDA ELECCIÓN } \\
\hline & Elecciones & $\begin{array}{l}\text { Partidos } \\
\end{array}$ & Votos & Escaños & Votos & Escaños \\
\hline \multirow{3}{*}{ Aguascalientes } & 1995 y 1998 & PRI & 37.63 & 11 & 38.31 & \\
\hline & & PAN & $\$ 8.93$ & 13 & $\$ 9.80$ & 16 \\
\hline & & PRD & 6.75 & 1 & 8.02 & 2 \\
\hline \multirow{3}{*}{ Baja California } & $\mid 1995$ y 1998 & PRI & 42.14 & 11 & 39.88 & 11 \\
\hline & & PAN & $\$ 8.30$ & 13 & +2.55 & 11 \\
\hline & & PRD & 5.04 & 1 & 10.13 & 3 \\
\hline \multirow[t]{3}{*}{ Guanajuato } & $199+$ y 1997 & PRI & 54.81 & 21 & 33.63 & 12 \\
\hline & 年 & PAN & 30.95 & 5 & 43.54 & 16 \\
\hline & & PRD & 8.62 & 2 & 13.49 & 3 \\
\hline \multirow[t]{4}{*}{ Jalisco } & $199+$ y 1997 & PRI & 43.42 & 23 & 35.76 & 17 \\
\hline & 年 & PAN & $\begin{array}{l}5.1 .72 \\
+0.73\end{array}$ & 12 & +2.55 & 2010 \\
\hline & & PRD & 7.50 & 1 & $15 .+1$ & 3 \\
\hline & & Otros & & 2 & & 2 \\
\hline \multirow[t]{3}{*}{ Nuevo Leín } & 1994 y 1997 & PRI & & & $\$ 10.34$ & it \\
\hline & & PAN & & & +9.16 & 24 \\
\hline & & PRD & & & 3.58 & 2 \\
\hline \multirow[t]{4}{*}{ Querétaro } & 1994 y 1997 & PRI & & 15 & +10.9 & 10 \\
\hline & & PAN & & 7 & +4.73 & 11 \\
\hline & & PRD & & 2 & 7.2 & 1 \\
\hline & & Otros & & 1 & & 3 \\
\hline \multirow{2}{*}{\multicolumn{7}{|c|}{$\begin{array}{l}\text { liaboración propia con base a los resultados clectoralcs de las Comisiones e Instituto Fistatales Filectorales. } \\
\text { (") Coalicion Alianza para cl cambio. }\end{array}$}} \\
\hline & & & & & & \\
\hline \multicolumn{7}{|c|}{$\begin{array}{l}\text { (*) Corresponde a diputados por mayoria relativa. } \\
\text { Nota: Los datos correspondientes a varios estados no fie posible locealizarlos. }\end{array}$} \\
\hline
\end{tabular}

\section{CONGRESOS LOCALES CON MAYORÍA PERREDISTA}

El triunfo de Cuauhtémoc Cárdenas como jefe de gobierno en el DF vino acompañado de otro del PRD en los 38 distritos electorales, lo que le garantizó la mayoría absoluta de la Asamblea Legislativa de esa jurisdicción electoral. A ese triunfo se le sumarían los de algunos estados donde producto de la alianza, especialmente con políticos ex priistas y partidos pequeños y, en el caso de Nayarit, con el PAN, provocaron mayorías absolutas en Baja California Sur y Nayarit, no así en Zacatecas donde el triunfo para la cámara de diputados fue a favor del PRI.
Mención especial es el caso de Morelos, donde el PRD tiene el mismo número de diputados que el PRI y hace mayoría absoluta con los legisladores del PAN. La experiencia legislativa en el DF cuando menos ha sido motivo de cuestionamiento por el peso que tiene la mayoría perredista, pero también acotada por las muchas de las prerrogativas constituciones que siguen siendo competencia del Poder Legislativo Federal.

\begin{tabular}{|c|c|c|c|c|c|c|}
\hline \multicolumn{7}{|c|}{ Cuadro 4: CONGRESOS LOCALES CON MAYORIAA PERREDISTA } \\
\hline \multirow[b]{2}{*}{ Estados } & \multirow{2}{*}{ Elecciones } & \multicolumn{3}{|c|}{ PRIMERA ELECCIÓN } & \multicolumn{2}{|c|}{ SEGUNDA ELECCIÓN } \\
\hline & & Particlos & Votos & Escaños & Votos & Escuños \\
\hline \multirow{4}{*}{$\begin{array}{l}\text { Baja California } \\
\text { Sur }\end{array}$} & 1996 y 1999 & PRI & 50.70 & 11 & 13.03 & \\
\hline & & PAN & 38.80 & 6 & 35.92 & 4 \\
\hline & & PRD & 3.10 & 2 & 47.73 & 12 \\
\hline & & Otros & & 2 & & \\
\hline \multirow[t]{4}{*}{ Distrito Federal } & 1994 y 1997 & PRI & $\$ 1.02$ & 38 & 24 & 11 \\
\hline & & PAN & 27.07 & 14 & 18.9 & 11 \\
\hline & & PRD & 13.27 & 12 & 43.7 & 38 \\
\hline & & Otros & & 2 & & 6 \\
\hline \multirow[t]{4}{*}{ Morelos } & 1994 y 1997 & PRI & 62.41 & 13 & +5.02 & 12 \\
\hline & & PAN & 9.59 & 11 & 15.89 & 5 \\
\hline & & PRD & 21.65 & 5 & 28.03 & 12 \\
\hline & & & & 1 & & 1 \\
\hline \multirow[t]{3}{*}{ Nayarit } & 1996 y 1999 & PRI & 53.60 & 20 & & 11 \\
\hline & & PAN & 27.80 & 6 & 51.17 & 19 \\
\hline & & $\operatorname{PRD}\left({ }^{*}\right)$ & $1+.60$ & 3 & & \\
\hline
\end{tabular}

*) Coalición Alianza para el Cambio integrada principalmente por el PAN y el PRD

\section{COMPETITIVIDAD ELECTORAL Y PARLA- MENTARIA LOCAL}

Aun cuando la competitividad ha sido considerada por Sartori (1980: 261-262) como "una propiedad o atributo" de la competencia democrática, es útil en sistemas con fuertes realineamientos electorales, como es el caso mexicano. En efecto, el proceso de cambio que se ha venido generando en el sistema de preferencias en las elecciones federales y locales ha elevado la competitividad de los partidos. Este índice, como se sabe en medios académicos, presta servicios para el estudio del rendimiento de los partidos políticos. Se trata de la influencia periódica que tienen los partidos en la masa de votantes y, consecuentemente, sobre el sistema de representación. Sus principales indicadores son: la proximidad en los resultados de los principales partidos como también la sucesión en el poder entre partidos de mayor o menor capacidad competitiva.

Los resultados que arroja nuestra investigación están expresados en el cuadro siguiente: en general, se aprecian tres tipos de desproporción entre la competitividad electoral y parlamentaria, grosso modo, estados de baja desproporción, es decir, aquellos donde oscila entre cero y diez, estados de desproporción meridiana, donde la diferencia oscila entre diez punto uno y veinticinco, y estados donde la desproporción es de veinticinco puntos y más.

La gran concentración entre los dos rangos nos muestra sistemas electorales con fuertes dosis de sobrerrepresentación, que viene siendo una característica de los sistemas políticos bipartidistas. La norma electoral favorece al partido mayoritario mientras castiga a las oposiciones, que no ven compensado su desempeño electoral con iguales márgenes de representación parlamentaria.

En México los niveles de competitividad de los partidos han aumentado significativamente en los últimos años. El PRI disminuyó en casi todos los estados sus niveles de vota- 
ción por debajo del cincuenta por ciento, el PAN superó en muchos la franja del treinta por ciento y en algunos logró triunfos de mayoría con más del cuarenta por ciento, lo mismo sucedió con el PRD, que hasta hace algunos años constituía todavía la expresión de una izquierda testimonial que no superaba, en el mejor de los casos, el quince por ciento. Hoy, como ya lo señalamos, gobierna en algunos estados y tiene un claro predominio en algunos legislativos locales.

\begin{tabular}{|c|c|c|c|}
\hline \multicolumn{4}{|c|}{ CUADR0 5: CONPETITINIDAD ELECTORAL Y PARLANIENTARIA LOCAL } \\
\hline Estapo & COMPETITIDAD ELECTOR.L & $\begin{array}{c}\text { COMPETHIIIDAD } \\
\text { PARLAMEATARLA (\%) }\end{array}$ & PARTIDOS \\
\hline Aguascalientes & 11.49 & $43.75 \quad(32.26)$ & PAN-PRI \\
\hline Baja Califernia & 12.67 & $0.00 \quad(87.33)$ & PAN-PRI \\
\hline Baja California Sur & 11.81 & $58.33 \quad(+6.52)$ & PRD-PRI \\
\hline Campeche & 6.81 & $36.84 \quad(30.03)$ & PRI.PRD \\
\hline Crahuila* & 20.89 & $94.7 \quad(73.81)$ & PRI-PAN \\
\hline Collima & +.5 & $30.00 \quad(25.5)$ & PRI-PAN \\
\hline Chiapas & 22.60 & $76.92 \quad(5+32)$ & PRI.PRD \\
\hline Chihuahua & 5.53 & $52.633(+7.1)$ & PRI-PAN \\
\hline Distrito Federal & 20.30 & $71.05 \quad(50.75)$ & PRD-PRI \\
\hline Durango & 9.6 & $64.28 \quad(54.68)$ & PRI-PAN \\
\hline Guanajuato & 991 & $25.00 \quad(15.09)$ & PAN-PRI \\
\hline Guerrero* ${ }^{\star \star}$ & $1+.82$ & $\begin{array}{ll}91.66 & (76.8+1)\end{array}$ & PRI-PRD \\
\hline Hidalgo & 25.72 & $55.55 \quad(29.83)$ & PRI-PAN \\
\hline Jalisco & 679 & $\begin{array}{ll}15.00 & (8.21)\end{array}$ & PAN-PRI \\
\hline Mésico** & 7.09 & $45.00 \quad(37.91)$ & PRI-PAN \\
\hline Michoacán & 5.17 & $\begin{array}{ll}77.77 & (72.60)\end{array}$ & PRI.PRD \\
\hline Marclos & 16.99 & $\begin{array}{ll}00.0 & (83.01)\end{array}$ & PRI-PRD \\
\hline Nayarit & 7.84 & $+2.10 \quad(34.26)$ & CAC**-PRI \\
\hline Nucvo Léńn & 8.82 & $41.66 \quad(32.84)$ & PRI-PAN \\
\hline Oaxaca & 12.96 & $(35.04)$ & PRI-PRD \\
\hline Puebla & 24.96 & $(\$+27)$ & PRI-PAN \\
\hline Qucrétaro & 3.83 & (5.26) & PAN-PRI \\
\hline Quintana Reo & 15.51 & $53.33 \quad(37.72)$ & PRI.PRD \\
\hline San Luis Potosí & 4.40 & $(2+.17)$ & PRI-PAN \\
\hline Sinaloa & 14.97 & (39.19) & PRI-PAN \\
\hline Sunora & 6.09 & (22.48) & PRI-PAN \\
\hline Talbasco & 22.60 & (19.50) & PRI-PRD \\
\hline Tamaulipas & 22.50 & $(+7.50)$ & PRI-PRD \\
\hline Tharcala & 16.55 & $(+2.27)$ & PRD-PRI \\
\hline Veracruy & 21.91 & $(52.16)$ & PRI-PAN \\
\hline Yucatán & 17.40 & (29.26) & PRI.PAN \\
\hline Zacatecas & 6.45 & $(10.21)$ & PRD-PRI \\
\hline
\end{tabular}

El cuadro 5 da cuenta de los nuevos niveles de competitividad de los partidos -si tomamos como base la enésima elección legislativa en cada estado-, los casos donde existe un predominio del PRI sobre el PAN como primera minoría, que son quince, van de una ligera diferencia de un poco más de cuatro puntos en los estados de Colima y San Luis Potosí hasta el casi veinticinco por ciento de los estados de Puebla y Veracruz; en tanto, la relación PRI-PRD va de un rango ligeramente superior al cinco por ciento de Michoacán hasta el veintitrés por ciento de Chiapas; por su parte, donde el PAN es gobierno las diferencias tienden a ser menores como lo muestra que en ningún caso rebasa el trece por ciento del total; una situación más holgada es el caso del DF donde la relación PRD-PRI llega a alcanzar diferencias superiores al veinte por ciento.

La competitividad parlamentaria tiene una correlación desproporcionada con relación al peso electoral de los partidos políticos. Así las cosas, la competitividad priista, que es el partido que tiene más parlamentarios en los congresos locales del país, se ve beneficiada por la desproporcionalidad que generan las leyes electorales de los estados. Así, los congresos de Coahuila (1994) y Guerrero (1996) presentan una clara tendencia a la sobrerrepresentación cuanto teniendo niveles que escasamente se aproximaban al quince y lige- ramente rebasan el veinte por ciento respectivamente, tienden hacia mayorías calificadas de sus congresos. Esta tendencia cambia prácticamente en todos estos legislativos cuando se reforman las leyes electorales y los partidos tienen una mayor presencia. Aun así, las diferencias entre la competitividad electoral y parlamentarias en donde el PRI domina siguen siendo las más altas mientras las del PAN y el PRD tienen un techo más bajo pero siguen siendo altas. Al fin, el formato de las leyes electorales en buena medida corresponden a la vieja institución del régimen político.

\section{COMPETITIVIDAD INTERPARTIDISTA}

Los estudios sobre competitividad interpartidista en sistemas democráticos frecuentemente tienen que ver con series largas de elecciones ya que sólo de esa forma es factible un análisis más pormenorizado de los márgenes de actuación de los partidos. En este trabajo que corresponde a un país que viene de un proceso de liberalización del régimen político sólo utilizamos dos elecciones donde son perceptibles cambios en las preferencias electorales de los ciudadanos. El PRI, por ejemplo, a mediados de los noventa tenía un desempeño electoral donde se combinaba triunfos muy apretados y muy amplios - con derrotas más o menos holgadas-. Una tendencia que cambia en la segunda mitad de los noventa. El PAN, en cambio, conforme a su estrategia gradualista comparte triunfos y derrotas estrechas. Finalmente, el PRD en sus primeros triunfos de gobernador logra triunfos más o menos holgados frente a su principal adversario.

El cuadro 6 da cuenta de cómo se han ido modificando la competitividad entre los dos principales partidos en dos periodos electorales: en la primera elección destaca que en el rango "muy estrecho" los triunfos son exclusivamente para el PRI y en una segunda elección es para los tres partidos, con triunfos electorales en la elección de gobernador. En el rango "estrecho" se observa un gran dinamismo pues en la primera elección el PRI y el PAN tuvieron un buen desempeño electoral, en la siguiente este rango se abrió coincidentemente con el avance del PRI y el PAN en varios estados de la República. En el rango "medio" es evidente el predominio que tiene el PRI sobre el resto de partidos ya que sólo el PRD se ubica en este nivel con su triunfo en el peninsular estado de Baja California Sur y el PAN en Aguascalientes. En tanto en el margen de "amplio" a "muy amplio" es notoria la pérdida de posicionamiento del PRI en varios estados y las dificultades del PRD y el PAN para lograr triunfos contundentes.

\section{PARTIDOS ELECTORALES Y PARTIDOS PARLAMENTARIOS}

En los estados mexicanos frecuentemente encontramos que, producto de la legislación local, el sistema de partidos presenta cinco partidos, pero en los hechos el propio proceso electoral tiene una tendencia a simplificarlos en el legislativo. La explicación más socorrida es la falta de asentamiento de los partidos pequeños y la escasa capacidad de convocatoria de las formaciones políticas regionales, toda 


\begin{tabular}{|c|c|c|}
\hline COADRO RE RASCO & 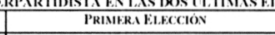 & 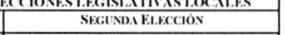 \\
\hline $\begin{array}{l}\text { Muy E. Errectoo } \\
(0-5) \text {. }\end{array}$ & $\begin{array}{c}\text { PRI Jalisco } \\
\text { BCS } \\
\text { Sinaloa } \\
\text { Durangu } \\
\text { Yucatin } \\
\end{array}$ & 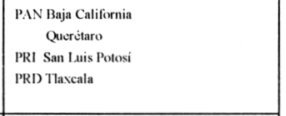 \\
\hline $\begin{array}{l}\text { Estrchoco } \\
(5.1-1-10)\end{array}$ & 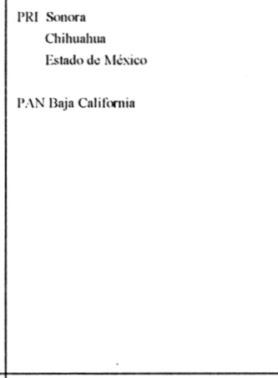 & 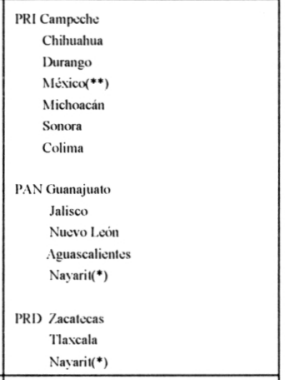 \\
\hline $\begin{array}{l}\text { Nedio } \\
(10.1-15)\end{array}$ & $\begin{array}{l}\text { PRI Znacalcas } \\
\text { Tamaulipas } \\
\text { DF } \\
\text { Pustla } \\
\text { Ilidalgo }\end{array}$ & 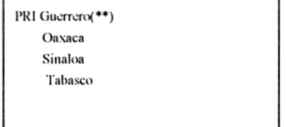 \\
\hline $\begin{array}{l}\text { Amprio } \\
\text { (15.5.-20) }\end{array}$ & $\begin{array}{l}\text { PAN Aguascalicntles } \\
\text { PRI Chiapas } \\
\text { Tabasco }\end{array}$ & $\begin{array}{l}\text { PRID Baja Califiomia Sur } \\
\text { PRI Morclos } \\
\text { Yucatan }\end{array}$ \\
\hline 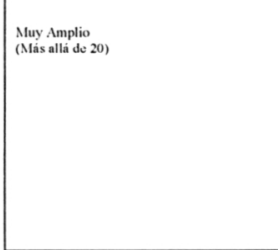 & 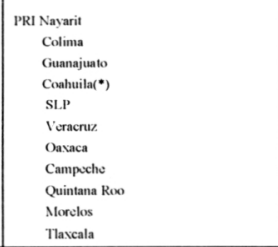 & 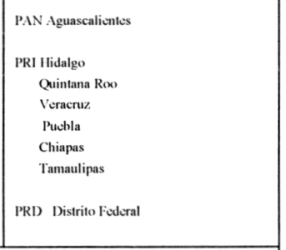 \\
\hline
\end{tabular}

vez que en muchos estados, como lo hemos podido constatar a lo largo de este trabajo, existe una tendencia claramente bipartidista cuando no son sistemas de partido predominante. Sin embargo, las bondades de una ley que en teoría busca tener un sistema más equilibrado de la representación nos permite observar, en cuadro 7 , que prácticamente la media de los estados cuenta con tres partidos políticos parlamentarios cuando no llegan al techo de seis partidos con representación en el congreso ${ }^{16}$. Lo que significa que, roto el bipartidismo en los congresos locales, se crean nuevos equilibrios que dan la pauta a los llamados partidos "bisagra”, que terminan siendo en determinadas circunstancias el fiel de la gobernabilidad.

Ahora bien, un dato que llama la atención en el citado cuadro es que los partidos gobernados por el PRI tienden a formar congresos de tres partidos, en tanto las oposiciones son tres y más partidos. Eso, se podría suponer, favorece una representación más diversa de los cleavages de la sociedad mexicana.

\section{FRAGMENTACIÓN ELECTORAL Y PARLAMENTARIA}

Este tipo de índice nos sirve para apreciar la relación del número de partidos y su tamaño. Asimismo, nos permite conocer la probabilidad de que "dos votantes seleccionados al azar opten por diferentes partidos en una elección, o la de que dos parlamentarios de una misma legislatura, también seleccionados al azar, pertenezcan a partidos distintos" (Montero, 1992: 243-297). El índice abarca de cero a uno. Es decir, cero significa que el sistema es

\begin{tabular}{|c|c|c|}
\hline \multicolumn{3}{|c|}{$\begin{array}{l}\text { CUADRO 7: NÚMERO DE PARTIDOS EIECCTORAIES Y PARI.ANENTARIOS } \\
\text { LOCALES EN 1998 }\end{array}$} \\
\hline & PARTIDOS EIECTORALES & PARTIDOS PARLANENTARIOS \\
\hline Aguascalientes & 5 & 3 \\
\hline Baja California & 5 & 3 \\
\hline Baja California Sur & 6 & 3 \\
\hline Campeche & 5 & 4 \\
\hline Coahuila (*) & 7 & 5 \\
\hline Colima & 5 & 3 \\
\hline Chiapas & 7 & 5 \\
\hline Chihuahua & 6 & 4 \\
\hline Distrito Federal & 6 & 6 \\
\hline Durango & 5 & 5 \\
\hline Guanajuato & 6 & 6 \\
\hline Guerrero $(\star \star)$ & 5 & 3 \\
\hline Ilidalgo & 4 & 3 \\
\hline Jalisco & 6 & 4 \\
\hline México(^^) & 6 & 6 \\
\hline Michoacín & 5 & 4 \\
\hline Morelos & 5 & 3 \\
\hline Nayarit(*ネ) & 6 & 2 \\
\hline Nuevo León & 5 & 4 \\
\hline Oaxaca & 5 & 3 \\
\hline Pucbla & 6 & 5 \\
\hline Quintana Roo & 5 & 4 \\
\hline San Luis Potosí & 6 & 3 \\
\hline Sinaloa & 5 & 3 \\
\hline Sonora & 5 & 3 \\
\hline Tabasco & 5 & 3 \\
\hline Tamaulipas & 7 & 3 \\
\hline Tlaxcala & 6 & 5 \\
\hline Veracru» & 5 & 4 \\
\hline Yucatín & 5 & 3 \\
\hline Zacatecas & 5 & 4 \\
\hline \multicolumn{3}{|c|}{$\begin{array}{l}\text { Número de partidos de la última elección local. En alguno de estos casos hubo coaliciones registradas } \\
\text { que incluy eron a uno o más partidos políticos con registro. } \\
\text { (*) Datos correspondientes a } 1994 . \\
(* *) \text { Datos correspondientes a } 1996 . \\
\left({ }^{* * *}\right) \text { Coalición Alianza para el Cambio integrada principalmente por el PAN y el PRD. }\end{array}$} \\
\hline
\end{tabular}

unipartidario en tanto el uno corresponde a un sistema multipartidista. Nuestras indagaciones en los legislativos locales nos exhiben distintos tipos de fragmentación electoral y parlamentaria. En esta forma la fragmentación electoral va de sistemas políticos bipartidistas hacia un sistema de tres partidos. En el nivel parlamentario la tendencia es a una mayor simplificación del voto ya que los dos primeros partidos tienden a absorber el mayor número de los escaños. Esto significa que mientras el sistema de competencia electoral exhibe escenarios multipartidistas en muchos congresos la tendencia es hacia el bipartidismo. Analizando casos como el de Chiapas, donde existe cleavage indígena y una oposición fuerte que encabeza el EZLN, la fragmentación es baja, con una fuerte inclinación hacia un sistema unipartidario. En cambio, en la capital de la república, una competencia más ordenada en los cauces institucionales favorece una alta fragmentación, lo que indica la existencia de un multipartidismo sólido.

\section{CONGRESO LOCALES, LEYES ORGÁNICAS Y REGLAMENTOS}

Los cambios electorales que se han escenificado en los estados de la federación han puesto a prueba el tinglado de normas y procedimientos de funcionamiento de los congre-

16. NOLHEN (1993:135) en un texto escrito a principios de los noventa concluía sobre el sistema de representación que "esta regulación no tiene, evidentemente, nada que ver con la implementación de un sistema proporcional... por el contrario comprueba el dominio absoluto del PRI sobre el resto del sistema de partidos". 


\begin{tabular}{|c|c|c|}
\hline \multicolumn{3}{|c|}{$\begin{array}{l}\text { CUADRO 8: FRAGMENTACIÓN ELECTORAL Y PARLAMENTARIA } \\
\text { EN LA ÚLTIMA ELECIÓN LEGISLATIVA LOCAL }\end{array}$} \\
\hline & \multicolumn{2}{|c|}{ FRAGMENTACIÓN } \\
\hline ESTADO & ELECTORAL & Parlamentaria \\
\hline Aguascalientes & 0.419 & 0.341 \\
\hline Baja California & 0.367 & 0.250 \\
\hline Baja California Sur & 0.373 & 0.185 \\
\hline Campeche & 0.400 & 0.514 \\
\hline Coahuila(*) & 0.359 & 0.364 \\
\hline Colima & 0.371 & 0.157 \\
\hline Chiapas & 0.350 & 0.746 \\
\hline Chihuahua & 0.433 & 0.544 \\
\hline Distrito Federal & 0.278 & 0.169 \\
\hline Durango & 0.258 & 0.135 \\
\hline Guanajuato & 0.320 & 0.469 \\
\hline Guerrero(^^) & 0.372 & 0.581 \\
\hline Ilidalgo & 0.340 & 0.404 \\
\hline Jalisco & 0.877 & 0.152 \\
\hline México (^n) & 0.276 & 0.150 \\
\hline Michoacán & 0.301 & 0.353 \\
\hline Morelos & 0.306 & 0.314 \\
\hline Nayarit (*^^) & 0.364 & 0.482 \\
\hline Nuevo León & 0.405 & 0.775 \\
\hline Oaxaca & 0.363 & 0.810 \\
\hline Puebla & 0.374 & 0.753 \\
\hline Querétaro & 0.348 & 0.221 \\
\hline Quintana Roo & 0.414 & 0.278 \\
\hline San Luis Potosí & 0.344 & 0.118 \\
\hline Sinaloa & 0.354 & 0.721 \\
\hline Sonora & 0.313 & 0.387 \\
\hline Tabasco & 0.477 & 0.483 \\
\hline Tamaulipas & 0.350 & 0.472 \\
\hline Tlaxeala & 0.278 & 0.370 \\
\hline Veracruz & 0.324 & 0.854 \\
\hline Yucatán & 0.431 & 0.293 \\
\hline Zacutecas & 0.322 & 0.279 \\
\hline \multicolumn{3}{|c|}{ 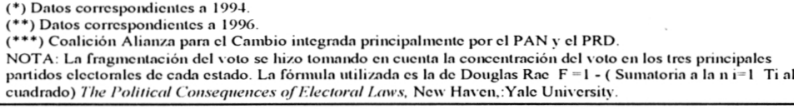 } \\
\hline
\end{tabular}

sos locales. No podría ser de otra forma cuando muchos de estos ordenamientos fueron creados en los mejores tiempos del sistema de partido hegemónico y, al menos para el PRI, existen pocos incentivos para promover modificaciones en sus aspectos más sustanciosos que favorezcan la nueva pluralidad política, al mismo tiempo que hagan del congreso una instancia más institucional y menos sujeta a los vaivenes políticos locales.

La agenda para la Reforma del Estado, que fue elaborada con motivo de la iniciativa presidencial de enero de 1995, pero también por el trabajo durante dieciocho meses de los líderes de las fracciones parlamentarias contemplaba, entre otros temas, la reforma constitucional del poder legislativo y la relación del Poder Ejecutivo con los estados de la república.

Sin embargo, el esfuerzo de convocatoria del presidente como el de los parlamentarios sólo propiciaría una reforma constitucional, que en el verano de 1996 facilitó la discusión de un nuevo código electoral que regularía las elecciones federales de 1997, así mismo, sentó las bases constitucionales para que en los estados se llevaran a cabo las reformas que derivarían en legislaciones que garantizaran una mayor equidad, transparencia y legalidad de los resultados electorales. Esto, como se puede constatar en los resultados electorales que hemos utilizado, favoreció una competencia más fluida entre los tres principales partidos como también un cambio significativo en la geografía electoral y en la integración de los congresos locales.

Justamente, estas reformas, que tienen como objetivo alcanzar un régimen de competitividad plena, hacen cada día más necesarias la de las leyes que regulan las relaciones entre los poderes de la Unión.
Esto que pudiera implicar un cambio de régimen político -ir de un sistema presidencialista a uno parlamentario o semipresidencial-, no podría dejar de tomar en cuenta el estado en que se encuentra la transición mexicana a la democracia que plantea, antes que cualquier cambio de fondo, reformas que gradualmente garanticen la gobernabilidad interna de los estados federados.

Este puente plantea la base sobre la cual se podría propiciar un cambio en el poder legislativo local. Tanto en lo que se refiere a las reformas constitucionales de los estados, como también de sus leyes orgánicas y sus reglamentos, que podrían terminar en ordenamientos más acordes con los nuevos equilibrios que tienen los congresos de los estados para garantizar de esta forma nuevas reglas de operación, eficiencia y productividad y, sobre todo, orden al debate legislativo.

En una investigación en curso sobre las leyes orgánicas y los reglamentos interiores de gobierno interior ${ }^{17}$ de los congresos locales, así como propuestas hechas en medios académicos, hemos podido constatar que la mayoría de estos ordenamientos se caracterizan por su obsolecencia. De ahí que cualquier iniciativa de reforma debería partir de sus flancos más débiles y los que garantizan una mejor y más eficaz contribución a una mayor institucionalización de un nuevo sistema de reglas.

\section{REELECCIÓN DE LOS DIPUTADOS}

La proclama de Francisco I. Madero ("sufragio efectivo, no reelección") que enarboló en contra de la dictadura de Porfirio Díaz lo hizo propio el constituyente de 1917 para la elección presidencial. Asimismo, fue aplicado a los legisladores a partir de $1933^{18}$ cuando se elimina esta facultad que garantizaba la permanencia inmediata en el Congreso de la Unión y, como tal, derivaba su aplicación a los estados de la federación.

El objetivo de esta medida constitucional fue lógico en un sistema político con pretensiones omnicomprensivas ya que pretendía con este "candado" evitar el patrimonialismo de la representación política en las regiones del país. No podemos olvidar que el PNR surge como la expresión de los poderes fácticos locales y alimentó su vocación patrimonial del poder político local. Sólo que cuando estos poderes locales fundan el PNR, más que para la lucha política interpartidista era para entrar al "México de las instituciones", delegan parte de su poder en el presidente de la república. Éste a su vez en su calidad de jefe de la coalición gobernante la

17. Este proyecto de investigación a cargo del autor de este artículo se desarrolla en el ambiente del Centro de Investigaciones Sociales de la Universidad Autónoma de Sinaloa y cuenta con el apoyo oficial del Instituto de Investigaciones Legislativas del Congreso de la Unión.

18. Existe un malentendido histórico cuando se mete en un mismo saco el principio de no reelección del Ejecutivo que tiene como fuente de inspiración el constituyente de 1917 y la de los legisladores que se resuelve luego de los debates de 1932-1933. Para una revisión sobre el tema como también de las propuestas que se han hecho para modificar el principio de no reelección parlamentaria recomendamos el trabajo de Benjamin HiLl y Fernando F. DWORAK (1998):"Elección Parlamentaria: escenarios y Desafios", en Voz y Voto, Núm.66. Agosto. 
hace extensiva a los estados donde el gobernador hasta hace poco tenía capacidades discrecionales y consultivas para influir sobre la integración de los grupos de poder en los congresos locales.

La negativa de la reelección inmediata e indefinida -las constituciones políticas de los estados establecen que un ciudadano sólo puede reelegirse como diputado cuando pasa una legislatura donde ocupó un escaño- ya no tiene sentido político y, por lo tanto tampoco jurídico, cuando los congresos dejaron de ser unipartidarios y cada vez más obedecen mas a la lógica de un sistema multipartidista.

Los legisladores responden no sólo a los intereses de sus propios partidos sino también a los agrupamientos surgidos como representantes de la denominada sociedad civil, los cuales han tenido un papel clave en los nuevos movimientos sociales y han transformado los mecanismos de promoción política en los propios partidos.

Quizá, el debate iniciado ya hace algunos años sobre este tema, ha puesto a discusión varios niveles de lo que representa la vigencia de este artículo para el trabajo parlamentario que hasta ahora responde a un tipo de mayorías que ya no lo es en muchos de los estados de la federación. Esto es, la reelección como un valor parlamentario que favorece el:

1. Fomento a la profesionalización del legislador de carrera de tal suerte que eleve su desempeño parlamentario dependiendo más de los electores que de las estructuras partidarias corporativas $y$, mucho menos, como frecuentemente sucede en el nivel local, que los diputados sean piezas de ajedrez de los poderes fácticos regionales.

2. Incentivo de una nueva cultura parlamentaria que conjugue la experiencia y la negociación con el resto de los partidos representados.

3. Y, finalmente, que eleve el nivel de rendimiento de los congresistas por legislatura ya que sólo mediante ésta vía el político/legislador estará en condiciones competir en la siguiente elección.

La experiencia de reelección intermitente en las legislaturas locales es la misma que en el Congreso federal ${ }^{19}$. Sólo muy pocos de los diputados se reeligen y, frecuentemente, cuando lo hacen se encuentra diferida a varías legislaturas producto de la gran demanda de promoción en los partidos. Ésto, como se sabe, se ha transformado en un grave problema para el trabajo legislativo ya que como se dice con cierta sorna, los diputados "en el primer año aprenden, en el segundo legislan y en el tercero buscan un nuevo trabajo". La posibilidad de una agenda para varías legislaturas es prácticamente imposible lo que se ha traducido en un bajo rendimiento parlamentario.

\section{Comisiones legislativas}

Las comisiones en los congresos locales, de acuerdo a la investigación señalada, son múltiples. Tanto por su número de integrantes, como también por el de las permanentes y no permanentes. No existe un patrón entre todas ellas. Existen congresos de los estados donde su número es limitado como en Baja California donde sólo existen 3 permanentes y los hay donde son 40 comisiones permanentes, como es el caso de Nuevo León. La media nacional es de quince comisiones y cada una de ellas tiene un promedio de cuatro miembros, los cuales como establecen muchas de las leyes orgánicas "no recibirán retribución extra por este trabajo". Incluso, entre éstas se encuentra un nuevo tipo de comisión como es la de Jalisco, Estado de México y Zacatecas donde el fenómeno político ha favorecido las dedicadas a los asuntos electorales. También en algunos estados existen comisiones encargadas del dictamen legislativo sobre tópicos novedosos como es el tema de los discapacitados, menores infractores y personas de la tercera edad, como sucede en los estados de Nuevo León y Durango.

La experiencia, sin embargo, en las comisiones y comités es que muchas de ellas se caracterizan por tener reglas poco claras lo que se traduce en iniciativas de bajo consenso pues en muchos de los legislativos sigue imperando la llamada "ley del más fuerte" que impone, o, en su defecto, neutraliza la iniciativa del contrario. Incluso, existen experiencias donde esta lógica corre en sentido inverso, es decir, donde las mayorías tradicionalmente opositoras imponen su punto de vista en las modificaciones a las leyes secundarias.

Las reformas grosso modo son imprescindibles en las leyes orgánicas y reglamentos interiores de gobierno y apuntan a los siguientes ejes problemáticos:

1. El principal problema que se observa tiene que ver con el excesivo número de comisiones que existe en un buen número de los congresos locales. Una muestra de ese exceso lo representa que mientras que el congreso federal tiene 26 comisiones permanentes, el congreso de Nuevo León 40; Chiapas, DF, Jalisco y Nayarit 30; Oaxaca, 26; Estado de México y Zacatecas 25 . Esto obliga a que, ante el gran número de comisiones, el excesivo trabajo parlamentario se caracterice por un bajo desempeño. Por ende, la reducción del número de comisiones y la reclasificación de sus funciones facilitaría que las iniciativas se transformen en verdaderos contrapesos del Ejecutivo estatal.

2. Más aun, cuando la obsolecencia de las leyes orgánicas y los reglamentos de funcionamiento de las comisiones y comités frecuentemente no establecen los límites de las facultades de sus coordinadores, secretarios y vocales.

3. La ausencia, por lo demás, de una instancia de coordinación entre los presidentes de las comisiones evita la promoción de iniciativas sobre asuntos de interés local, fortalecimiento de facultades en materia de audiencias públicas, consulta popular y comparecencias. Aunque en varios estados la ley orgánica establece puentes de cooperación entre los miembros de varias comisiones.

Los cambios que se han presentado en el nivel de las comisiones tienen que ver, aun cuando no existen reformas de fondo en las leyes orgánicas y sus reglamentos, con el papel que cumplen los integrantes de las comisiones que ya no siempre son de mayoría del PRI sino, como lo hemos visto a lo largo de este trabajo, de otros partidos. La Asamblea de

19. Cfr. A. Lutambio, ob cit, p. 174 y ss. 
Representantes del DF, por ejemplo, con una mayoría cómoda preside las principales comisiones y, en reiteradas ocasiones, la ha utilizado para imprimirle una dinámica similar a la de toda mayoría parlamentaria en comisiones ${ }^{20}$.

\section{SERVICIO PROFESIONAL DE CARRERA}

La baja productividad de los congresos locales, además de los problemas propiamente políticos, tiene que ver con el perfil de los diputados (nivel académico, motivaciones y expectativas), pero sobre todo, con la inexistencia en todos ellos de un servicio profesional de carrera que garantice apoyos técnicos extraordinarios a las fracciones parlamentarias para lograr un mayor y mejor rendimiento.

La ausencia de este tipo de instrumento de asesoría institucional provoca que entre los múltiples y diversos congresos locales las fracciones oscilen entre las que cuentan con apoyos profesionales que son muy pocos y frecuentemente exclusivos de los partidos grande y la que se forma a partir de los círculos de los partidos políticos como una forma de empleo partidario. En sondeos realizados en algunos de los congresos locales encontramos que el PRI es el partido que tiene con mayor frecuencia un staff profesional más consolidado, el PAN cada vez más prepara a sus cuadros de apoyo y el PRD, donde es tercera fuerza, tiene regularmente como asesores a militantes partidistas con escasa preparación legislativa.

La mayoría de estos congresos, por lo demás, no cuentan con institutos de investigaciones legislativas generadoras de ideas que estimulen nuevas dinámicas para una discusión más rica de sus asuntos. Incluso, los hay, congresos que no cuentan con bibliotecas especializadas y con órganos de expresión legislativa.

Algunos de los cambios dentro de la continuidad del congreso local, entonces, tendría que ver necesariamente con ampliar el abanico de servicios de apoyo como análisis políticos, proyectos de ley, etc., así como, unidades especializadas en materia política, económica, social y parlamentaria.

\section{GRUPOS PARLAMENTARIOS}

La nueva pluralidad del sistema político, la futura participación de más partidos de minoría y la eventual creación de un mayor número de partidos regionales, además de la necesidad de distinguir las funciones de concertación y conducción política de las propiamente del régimen interno y gobierno parlamentario, plantea la necesidad de redefinir la estructura y funcionamiento del órgano de gobierno de las cámaras locales.

En los estados de la federación, las funciones de gobierno (representación, organización y dirección) y de concertación política las desarrolla principalmente la Gran Comisión, que está integrada por un presidente, un secretario y siete vocales. Esta comisión del poder legislativo la detenta el partido que tiene la mayoría absoluta y dura el mismo tiempo de la legislatura. La mayoría opositora en la LVII legislatura del Congreso de la Unión evitó que esta comisión funcionara y sus responsabilidades quedaran en manos de la Comisión de Régimen Interno y Concertación Política, en la que participan los coordinadores de las fracciones parlamentarias. Esto mismo debe suceder en los estados para que el partido ganador de la elección legislativa no absorba tantas funciones y las responsabilidades tengan un carácter rotatorio.

La suma de responsabilidades en esta comisión plantea para el caso de los estados los siguientes cambios:

1. La Gran Comisión de los Congresos locales tendría que delegar responsabilidades en su Mesa Directiva.

2. Reformar los mecanismos de elección de los miembros de la Mesa Directiva quitando el carácter secreto y mayoritario para lograr mayorías absolutas del pleno del Congreso.

En lo que respecta a la gobernabilidad en el interior de las cámaras se requiere modificar el papel tradicional de los grupos parlamentarios. Entre las medidas de cambio que podrían propiciar mejores condiciones para el funcionamiento del órgano legislativo resultan necesarias las siguientes:

1. Reglas de participación democrática en los grupos parlamentarios.

2. Disciplina de órganos, de funcionamiento, de administración de su patrimonio y de la utilización de los recursos asignados por la Cámara.

3. En definitiva, mediante este tipo de cambios se evitaría una constante del congreso mexicano que viene siendo la toma de decisiones cupulares sobre mecanismos democráticos.

\section{FUNCIONAMIENTO LEGISLATIVO}

Una constante en los congresos locales es la ausencia de instrumentos y organismos que eleven su rendimiento legislativo. Esto supone crear nuevas iniciativas, como también modificar prácticas legislativas que no corresponden a la nueva pluralidad política. Una reforma de fondo de los legislativos locales pasa necesariamente por el reconocimiento de que muchos de sus elementos de continuidad deben ser cambiados para lograr hacer compatible pluralidad con un más eficaz sistema de reglas. Esto es:

1. Ampliar los periodos de sesiones del congreso para garantizar una regulación del proceso legislativo para lo cual son necesarias nuevas reglas específicas para la aprobación de reformas constitucionales, de la normativa interna, del presupuesto y, una tarea que escasamente ha cumplido el legislativo local pero es de fundamental importancia, la evaluación de los planes estatales de desarrollo.

2. Reformar el Poder Legislativo mediante una actualización de las leyes orgánicas y sus reglamentos interiores de gobierno. La mayoría de ellos datan de diez

20. Aun así faltan estudios específicos sobre la filiación partidaria de presidente y secretarios de comisiones tanto en estados donde se mantiene la hegemonía priista como también donde existen diferentes fórmu las de gobiernos divididos. Y, claro, en los estados donde se han creado nuevas mayorías parlamentarias. Habría que profundizar en estudios com parados sobre el tipo de avance que han tenido las reformas en ésta mate ria sobre todo cuando se han producido nuevos equilibrios legislativos locales. 
y más años, aunque justo es reconocer que estas mismas leyes han sido reformadas, lo que muestra el rezago que tienen con respecto de los cambios políticos que ha manifestado el poder político local.

3. Actualizar y reglamentar las funciones de supervisión y control del Poder Ejecutivo sobre todo cuando a escala ha fungido como el gran legislador en muchos de los estados de la federación.

Finalmente, sólo restaría agregar, parafraseando la tesis de Badie y Hermet, que cada parlamento está marcado por la huella de una historia, de una cultura... pero, sobre todo, por la voluntad que puedan tener los hombres de cambiar sus productos institucionales.

\section{CONCLUSIONES}

Este ensayo sobre el congreso local mexicano, nos permite concluir en primer término, que así como en el nivel federal existe una quiebra del acuerdo que garantizó la estabilidad política del país, en los estados de la federación viene sucediendo lo mismo. La crisis de las instituciones del viejo acuerdo político son manifiestas. Los conflictos postelectorales de los años ochenta prácticamente han desaparecido del país producto de la evolución del sistema electoral, sin embargo, es evidente que las reformas han sido insuficientes para dotar de un tinglado institucional que sea expresión de un nuevo pacto que necesariamente debe ser democrático. Más aun, cuando en los estados de la federación existen procesos de liberalización de varias velocidades lo que significa distintos desarrollos en su institucionalización. Las reformas constitucionales del verano de 1996 constituyen el principio de un acuerdo que debe pasar por el debate sobre la reforma del estado. Ya las evidencias que arroja este trabajo demuestra que estamos frente a nuevas realidades en los estados, lo que hace plausible la tesis de Alonso Lujambio de que el presidencialismo mexicano ya se encuentra acotado por los gobiernos opositores donde influyen decididamente los congresos locales.

Sin embargo, si compartimos la tesis de que en México no está en la mesa de discusión sobre la reforma del estado lo correspondiente al cambio de régimen -al menos así está claramente planteado en la agenda aprobada por dirigentes de los partidos y, la cual hoy en día, descansa el sueño de los justos- sino la eventual reforma de las instituciones existentes. En este sentido, los cambios que se han introducido a los ordenamientos del congreso federal para responder a la nueva pluralidad, como es la reciente aprobación por las dos cámaras de su nueva ley orgánica, debe ser atraída a los estados para que con imaginación se discuta, al mismo tiempo que incorpore lo que sirva a los nuevos equilibrios políticos regionales.

\section{BIBLIOGRAFÍA}

ADLER, Larisa y Frida GorBaCH (1998): "Entre la continuidad y el cambio: el ritual de la sucesión presidencial”, Revista Mexicana de Sociología, Vol. 60, núm, 3, jul-sept..

Badie, Bertrand y Guy Hermet (1993): Política Comparada. México: FCE.

CARrILlo, Ulises y Alonso Lujambio (1998): "Gobierno dividido y aprobación presupuestal en la LVII legislatura del Congreso Mexicano, 1997-2000", en Revista Mexicana de Sociología, vol.60, núm. 2, abril-junio.

HERNÁNDEZ, Ernesto (1997): La liberalización política mexicana: legislación y procesos electorales en los estados de Baja California, Michoacán y Sinaloa. México: EdiUAS.

HERNÁNDEZ, Ernesto (1999): "Reforma de Estado, gobernabilidad y democratización en México (un esquema para el análisis)”, en Democracia, reforma del Estado y gobernabilidad. Revista Sinaloense de Ciencias Sociales. Num.3-4.

LinZ, Juan y Arturo VALENZUELA (comps) (1996): The failure of presidential democracy. Comparative Perspectives. Baltimore: John Homkins University Press.

LOAEZA, Soledad (1996): "Liberalización política mexicana", en COOK María Lorena et al "Las dimensiones políticas de la reestructuración económica". México, Cal y Arena.

Lujambio, Alonso (comp.) (1996): Gobierno divididos en la federación mexicana. México: UAM-IFE-Colegio Nacional de Ciencias Políticas y Administración Pública.

MidDlebroOK, Kevin J. (1998): "La liberalización política de un régimen autoritario: el caso de México”, en G. O’DonnelL, P.C. SCHMitTER y L. WhitehEAD (comps), Transiciones desde un régimen autoritario: América Latina. Buenos Aires, Paidós.

MonTERO, José Ramón (1992): “Las Elecciones Legislativas”, en Cotarelo, R. (comp.), Transición Política y Consolidación Democrática (1975-19869). Madrid: Centro Investigaciones Sociológicas.

NolHEN, Dieter (1993): Los sistemas electorales en América latina y el debate sobre la reforma electoral. México: UNAM.

PACHANO, Simón (1998): "Presidencialismo y parlamentarismo", en Revista Mexicana de Sociología, Vol. 60, num. 3 julio-septiembre. México: IIS-UNAM.

PARAmio, Ludolfo (1991): "El final de un ciclo y la crisis de unos actores: América Latina ante la década de los noventa”, en Revista de Estudios Políticos, núm. 74. Madrid: Centro de Estudios Constitucionales.

PITKIN, Hanna (1967): The concept of Representation. Berkeley: University of California.

SARTORI, Giovanni (1976): Partidos y Sistemas de Partidos I. Madrid: Alianza Universidad.

Lujambio, Alonso (1996): Federalismo y Congreso en el cambio politico de México. México: UNAM.

WoldENBERG, José (1997): "Alcances de la Reforma Electoral de 1996", en Revista Arenas, Primera Epoca. Núm.1.

- Leyes orgánicas de los congresos locales mexicanos

- Revista Voz y Voto. 